\title{
A 27-year perspective on landscape ecology from the US-IALE annual meeting
}

\author{
Nancy E. McIntyre • Louis R. Iverson • \\ Monica G. Turner
}

Received: 28 August 2013/Accepted: 21 September 2013/Published online: 26 September 2013

(C) Springer Science+Business Media Dordrecht 2013

Among the three of us, we have attended every annual meeting of the U.S. Chapter of the International Association of Landscape Ecology (US-IALE), and at least 20 meetings each. There have been several reviews of published research from the journal Landscape Ecology that have suggested a need for or documented a trend of moving away from purely descriptive studies quantifying pattern towards more technologically and analytically rigorous examinations of processes occurring over a wider range of spatiotemporal scales to guide design and management activities (Wiens 1992; Hobbs 1997; Andersen 2008; Wu 2013). Annual conferences can provide a different perspective on a field. To provide a unique temporal perspective on how themes of landscape ecology research in the U.S. have ebbed and waned, we examined and classified each oral presentation or

\footnotetext{
N. E. McIntyre ( $\square)$

Department of Biological Sciences, Texas Tech

University, Lubbock, TX 79409-3131, USA

e-mail: nancy.mcintyre@ttu.edu

L. R. Iverson

Landscape Change Research Group, Northern Research

Station, USDA Forest Service, 359 Main Road, Delaware, $\mathrm{OH} 43015$, USA

e-mail: liverson@fs.fed.us
}

\section{G. Turner}

Department of Zoology, University of WisconsinMadison, 430 Lincoln Dr., Madison, WI 53706, USA

e-mail: turnermg@wisc.edu poster title from the abstract books prepared for each meeting, beginning with the first conference in 1986. The 1991 and 1999 World Congresses were included because they also served as the US-IALE meetings in those years; all other Congresses during the time frame were held in addition to US-IALE meetings and so were excluded from analysis (Table 1).

We categorized talks and posters based on 17 nonmutually exclusive categories:

Climate change

Connectivity-including movement, percolation

Conservation

Design/planning

Diseases/pests/invasive species

Disturbance

Fire

Fragmentation

Historical patterns

Landscape genetics

Methodological

Metrics/indices

Natural resource management

Pattern description

Scale

Urban

Other

Based on its title, each presentation $(N=5947)$ was assigned to these categories; most presentations belonged to 1-3 categories (maximum turned out to be five). These categories are not exhaustive, of 


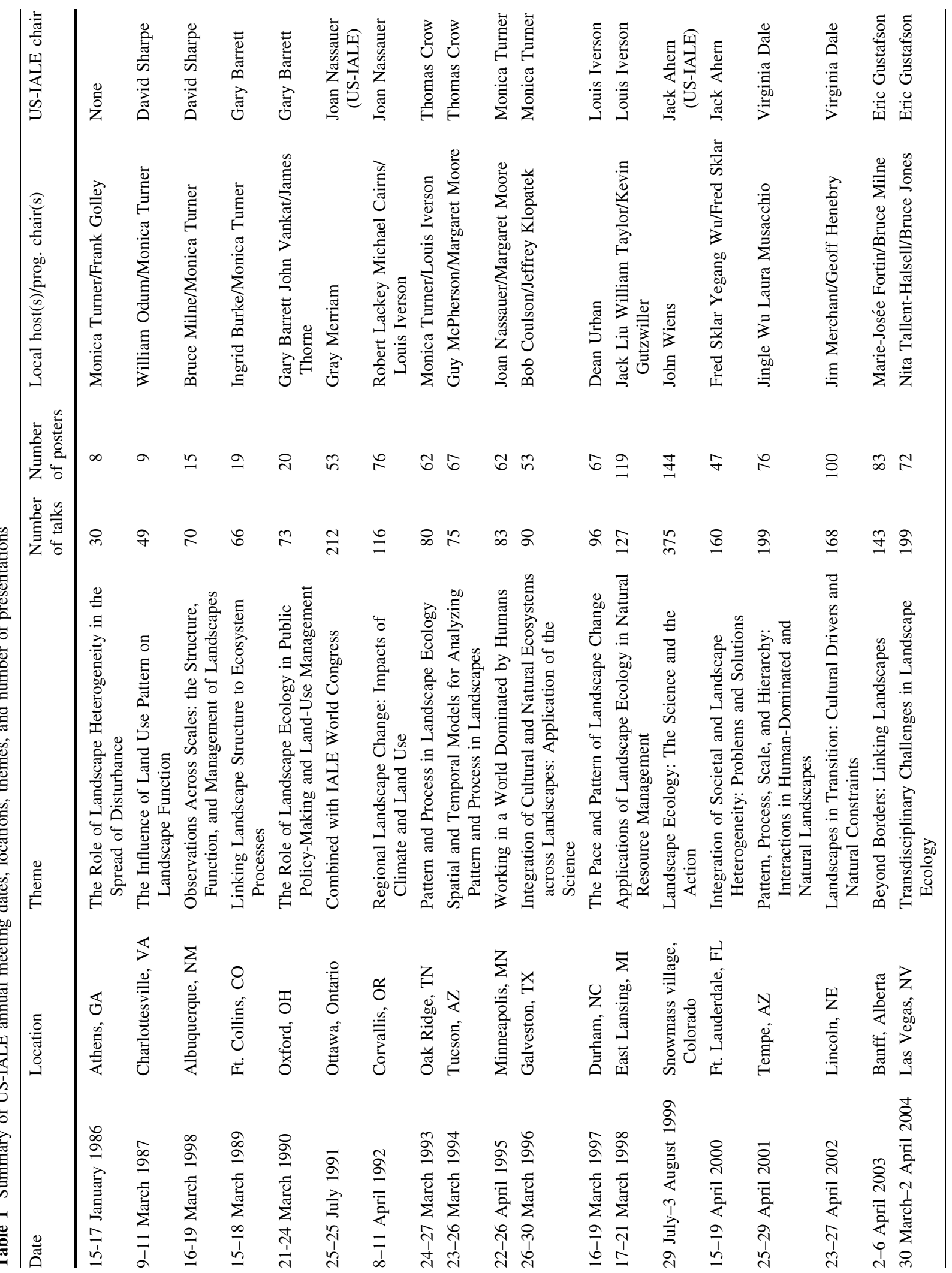




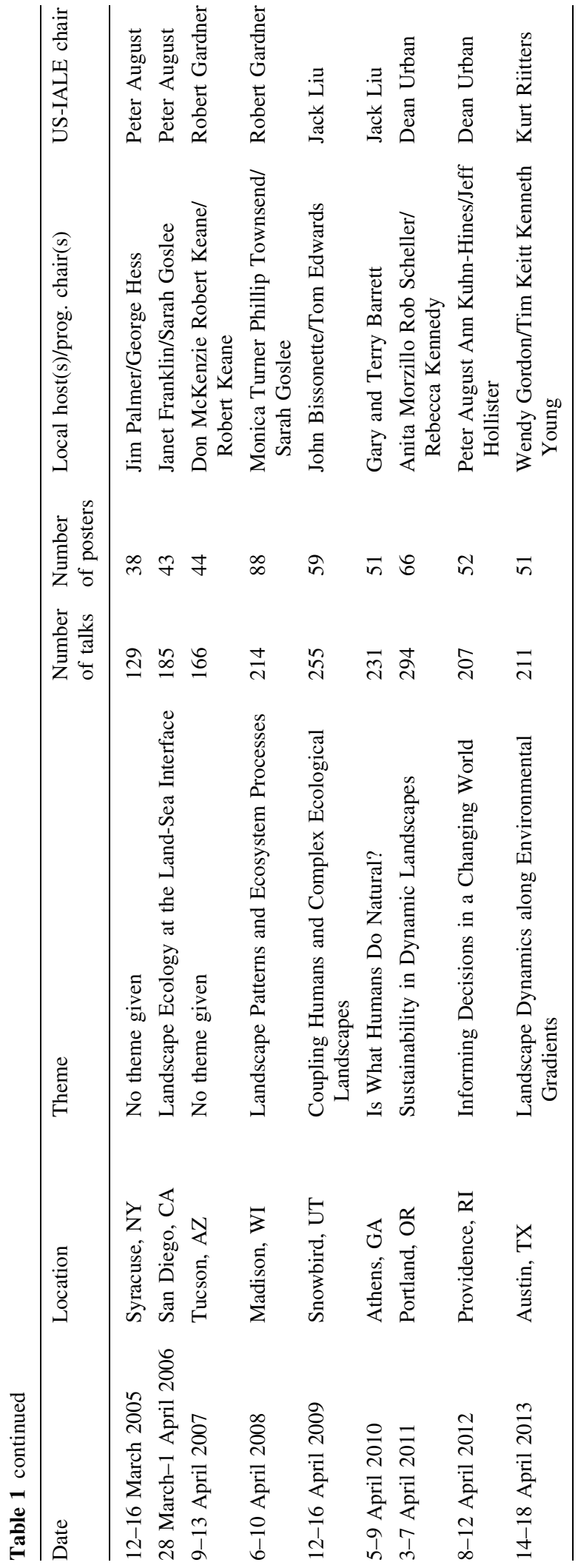

course, but they do include the central themes of the pattern/process/design triumvirate of landscape ecology (e.g. scale, fragmentation, connectivity), as well as some emerging areas of interest (e.g. climate change, urbanization, landscape genetics). Some topics are also somewhat redundant (e.g. fire is a type of disturbance, but presentations on fire were only categorized as fire). For purposes of this summary, we did not include last-minute changes to the program, workshops, and plenary talks, nor did we include introductions and summaries of symposia.

The number of presentations in any given year ranged from 38 (1986, the first meeting that also led to the formation of US-IALE) to 519 (1999, when the annual meeting coincided with the World Congress), so we report the proportion of presentations on each topic in an effort to normalize among years (Fig. 1). Spikes in certain topics in some years may reflect these differences in attendance as well as the inclusion of special sessions or symposia on a given subject (e.g. disturbance in 1986, landscape genetics in 2013).

Like the reviews of published research within the discipline (Wiens 1992; Hobbs 1997; Andersen 2008; $\mathrm{Wu}$ 2013), we found foci on land cover change, scale and scaling relationships, and applying landscape ecological principles to conservation, management, planning, and design. Overall, landscape ecology is still largely driven by a focus on pattern (not surprising, given that spatial heterogeneity is central to the discipline, and describing pattern is a necessary first step in much landscape ecological research) and on the development of methods to quantify the relationships between pattern and process (Fig. 2). Some topics, such as fire and connectivity, have been represented consistently over the years; other topics, such as climate change, landscape epidemiology, and invasive species, have surged in recent years (Figs. 1, 2). There are many topics included in the "Other" category that are now, or were for a period, research foci in landscape ecology in their own right (e.g. soundscapes, species distribution modeling), providing evidence of the dynamic ability of the field to address new challenges (see also Wu 2013). An area of concern is the relative decline in the proportion of presentations devoted to landscape design, landscape architecture, or planning (Figs. 1, 2), evidence of a need for resurgence of the valuable mixing of ecological and planning/design disciplines at the annual meetings. 
Fig. 1 Frequency plot of the 17 presentation categories by year, 1986-2013. Categories are arranged along the $\mathrm{Z}$-axis according to their overall abundance, from least to most common topics (front to back)

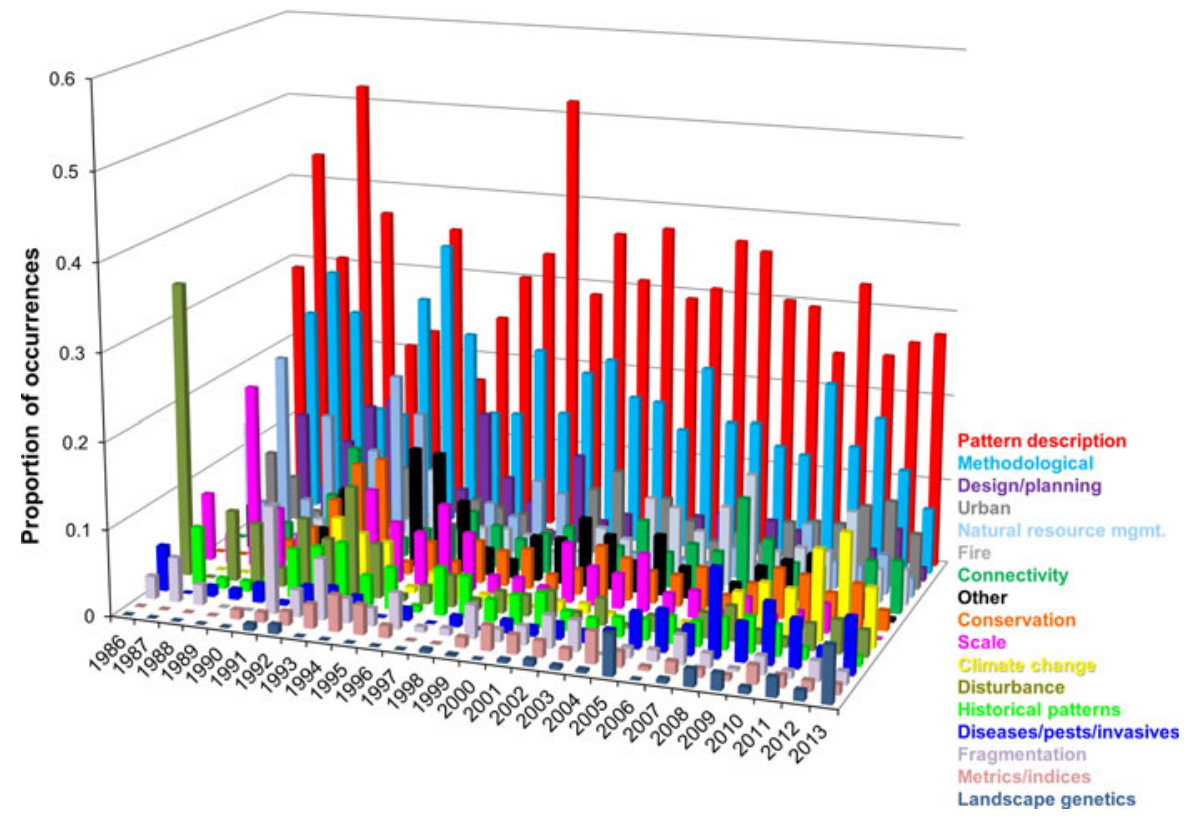

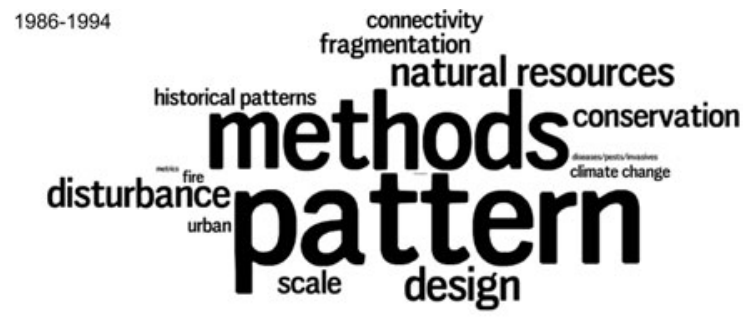

1995-2003

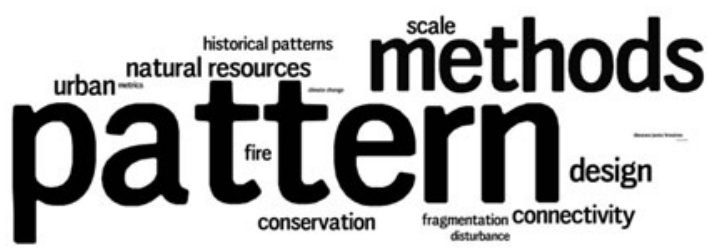

2004-2013

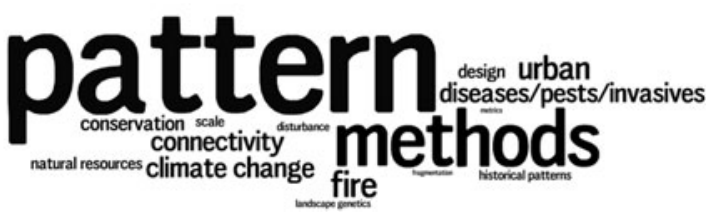

Fig. 2 Word clouds (www.wordle.net) of 16 presentation categories (excluding "Other") examined for three equal time periods (1986-1994, 1995-2003, 2004-2013). Size of each word is scaled by frequency of occurrence

As three landscape ecologists who have built longlasting professional relationships with the people we have met at the annual meetings, we can also attest to the value of regular attendance that goes beyond the presentations. For students and early professionals, this aspect is of particular value. Beyond the usual networking opportunities that any scientific conference delivers, the US-IALE annual meeting provides a wealth of activities for students (including the studentmentor luncheon, the "We'll Pick up the Tab" meet and greet that introduces students to non-student/more senior attendees, the student social, and presentation awards), early-career scientists (participation is neither student-dominated nor senior scientist-dominated), and more seasoned participants (workshops). Consistent participation in a meeting has given us a perspective of landscape ecology that cannot be gained in any other way, so we urge you all to do the same with the US-IALE annual meeting. We hope you can make it to Anchorage in 2014 and Portland in 2015!

\section{References}

Andersen BJ (2008) Research in the journal landscape ecology, 1987-2005. Landscape Ecol 23:129-134

Hobbs RJ (1997) Future landscapes and the future of landscape ecology. Landsc Urban Plan 37:1-9

Wiens JA (1992) What is landscape ecology, really? Landscape Ecol 7:149-150

Wu JG (2013) Key concepts and research topics in landscape ecology revisited: 30 years after the Allerton Park workshop. Landscape Ecol 28:1-11 